\title{
HOOKED ON AN AfFECT: Detroit Techno and Dystopian Digital Culture
}

\author{
$\bullet$ Feature Article $\longrightarrow$ \\ RICHARD POPE \\ RYERSON UNIVERSITY
}

\begin{abstract}
Detroit techno is typically historicized as having grown out of the late 1970s and early 1980s middle-class, consumerist, and aspirational high school social party scene, giving the impression that Detroit techno artists created forward-thinking music as a means to acquire subcultural capital and (re)produce their identities. In this essay, this position is nuanced for a more complex understanding of techno's relation to the quotidian phenomenological encounter with the dystopian setting of Detroit. Concomitantly, predominant theorizations of affect within the humanities, which emphasize the utopian, hopeful dimensions of affect's inherent productivity, are supplemented for an understanding of productive energy revolving around affects of dystopia and on a certain hopelessness which scholars, in the years ahead, will increasingly have to negotiate.
\end{abstract}

KEYWORDS: techno, Detroit, dystopia, affect, aesthetic, desire, subculture

Richard Pope is a Postdoctoral Fellow at Ryerson University. His recent work examines the dystopian horizon of contemporary capitalism and popular culture. He has published previously in Camera Obscura, Space and Culture, Film-Philosophy, and Cinema Journal (forthcoming). 
${ }^{C}$ Without sounding too new-agey or metaphysical, I think that Detroit, the actual location of Detroit, is the instigator behind everything.

-Jason Huvaere (in Sicko 2010: 92)

It's the emptiness in the city that puts the wholeness in the music. It's like a blind person can smell and touch and sense things that a person with eyes would never notice. And I tend to think a lot of us here in Detroit have been blind to what was happening around us. And we sort of took those other senses and enhanced them, and that's how the music developed.

—Derrick May (in Reynolds 1999: 21)

IN 1956, THE PACKARD AUTO PLANT, once proud manufacturer of luxury vehicles, shuttered its doors. In the early to mid-1990s, it was one of the primary venues where second-wave Detroit techno DJs played to growing crowds. Now, with much of it collapsed and in ruins, it is picked at day by day for whatever value its materials may still hold; city officials, long wanting to demolish the Albert Kahn-designed building, cannot even sort out who owns the 3,500,000 square-foot, thirty-six acre facility (Bowman 2010). Near the end of Requiem for Detroit (2010), a Julien Temple documentary for the BBC, an "urban explorer"-a Detroit native-serving as the British director's guide remarks that, in intersecting Detroit's industrial past and post-industrial present and future, the Packard plant is, if not the geographical center of the city, its metaphysical or spiritual heart. With its "low droning heartbeat”, he suggests moreover that Richie Hawtin's aka Plastikman's 1996 track "Packard" poignantly reproduces the experience of the abandoned plant. For this native, the music, the view, and the city itself cannot be disassociated; instead, a certain affect knots them all together, there where he stands-but a "there" which, in his peripatetic "explorations" and dystopian flânerie, is at once everywhere and nowhere. Even as it is the rise and fall of an industrial economy that has marked Detroit's unenviable fate, survival in this dystopian setting will, he intuits, require a technological disposition-or rather, it will require a techno sensibility, means or craft absented motive and systematic order; tekhne without logos, the cyberpunk, survivalist modus operandi (see McCutcheon 2007: 269).

With the ongoing implosion of the global economy it has become increasingly evident that Detroit's fate marks the future of all cities and countries in (what has passed from the "developed" to) the undeveloping world. The ostensible economic gains of the oncemuch-lauded "post-industrial" economy, we learn more and more each day, were chimeric, achieved only through self-perpetuating boosterist bubbles and rising debt levels; this oncerising standard of living, designated experts and politicians now chime in near-unison, is never coming back. As the "knowledge economy" is increasingly revealed as a dissimulation 
we are left face to face with the ruins of modernity, literally in the case of Detroit. The most tragic aspect of the end, the dreaded "apocalypse" which has thereby already happened, is that we will never be able to point to an event which precipitated this demise, for it is in the nature of this demise to have foreclosed the historical dimension by which we might recognize just such an event. For Detroiters, there is, despite the failed attempts to point to the race riots of 1967, no one event which precipitated the demise of the city, but rather an interminably long series of events and, moreover, "structural transformations", piling one on top of the other like the ruins of the city (see Herron 1993). If, as Lacan once retorted to his headstrong students in May 1968, structures do walk the streets (in Žižek 2004: 131), in Detroit the deconstruction or demise of the dominant structures of modernity walks the streets, though this experience is best captured not by the famed Parisian stroll but by the drive-by or drive-through - or by riding the People Mover which improbably travels, in one direction only, between Detroit's abandoned skyscrapers. Whereas the Baudelairean flaneur went walking in search of modernity, Detroit's "urban explorers" and residents search for, or are rather confronted by, modernity's demise.

If the ontological oblivion of "late capitalism" (the expression deserves a new lease on life) ${ }^{1}$ is typically forgotten through praxis, through our going about our everyday lives shuffling between work and family and television, Detroit techno, as our native, Jason Huvaere, and Derrick May imply, implicitly—sometimes explicitly—confronts this oblivion. It does so, in part, by simply observing and playing to the real of its environment, but also, and concurrently, by remediating and developing prior imaginings of the future. Unsurprisingly, Detroit techno's realization of the ontological oblivion of late capitalism was and is mediated or filtered through prior cultural imaginaries; looking forward, it also looks back to prior imaginings of the future according to a retrofuturist logic. However, Detroit is unique in that many of these fictional imaginings of the future are physically etched into and as Detroit's cityscape; built as a utopian vision of the future, in Detroit one must face, everyday, the reversibility of utopian capitalist fantasy and partial reality into dystopian capitalist reality. Fixated on the Real of dystopian affect, Detroit techno thereby marks a kind of shadow culture for those who do not turn their radar away from the dystopia of the dehistoricized and desubstantialized present and the "future" which is its necessary result. Indeed, in Detroit there is a certain slippage between the Real as the impossible, structurally excluded from discourse and experience, and the Real as something which one "experiences" face-to-face on a daily basis; Detroit's real continually (re)becomes Real.

As such, Detroit techno should remain differentiated from more popular European forms of techno; whereas the former is rooted in the dystopian Detroit experience, the latter is often associated with the utopian "eu(ro)phoria" that greeted the fall of the Berlin Wall in 1989 (Sicko 2010: 38). That is to say, according to the retrofuturist, Adornian, and Badiouan gambit of this essay, one should remain faithful to the artistic "truth-event" of Detroit techno while staying cognizant of the ways in which it has potentially been betrayed, in more recent years, by the global growth of celebrity DJ culture. A common complaint of Detroit techno aficionados, of course, is that they repeatedly propagate myths about the 
supposed uniqueness or purity of the form. Rather than denounce these gestures as retrograde, however, they should be affirmed to the extent that claims of the music's authenticity are addressed not towards a purity of presence/essence but on the contrary towards the onceeffective affective realization of the demise of presence, of logos, in an era in which the form was defined by techno DJs proliferating heteronyms and confounding interviewers.

In what follows, I will argue against two predominant readings of Detroit techno. In the first, Detroit techno is historicized as having grown out of the high school social parties that sprung up in and around Detroit in the late 1970s and early 1980s. I will argue for Detroit techno's break from the consumerist and aspirational nature of this party circuit. In the second-which in some cases follows from the first-many readings of Detroit techno delimit a utopian sensibility to its music and philosophy. Arguing that this belief is misplaced, I concomitantly supplement predominant theorizations of affect that emphasize the utopian dimensions of affect's inherent productivity. Even when studies and theories of affect note how it is regressively harnessed by the Right, they invariably end on a hopeful note that ambiguously outlines the possibility of the Left, if not capturing affect for meaningful purposes, learning to live in its productive traces. In an era in which capitalism increasingly relies upon the production and circulation of hopeful affect, this argumentation leaves one at a certain critical impasse. Relatedly, this line of argument renders impossible the analysis of Detroit techno, whose productive and critical spirit evidently revolves around affects of dystopia and thus on a certain hopelessness. Of course, the perennial hopeful turn of criticism is understandable; absent of such "optimism of the will", many scholars wouldn't put finger to keyboard. But what if, in the place of advocating an optimistic outlook upon the acknowledgement of the ongoing demise of "metanarratives" and symbolic culture, we remained at the level of, and, if not definitively came to terms with, grappled and tackled, the demise itself-what if, like so many presently undertheorized aspects of our culture, we remained, precariously, looking out at the broken horizon, hearing, like our wandering guide, a certain track?

\section{AfFECT TURNS:}

\section{From Hopeful Ethics to the Cultural Politics of Radical Pessimism}

ONE of the primary arguments of the "affect turn" within the humanities has been that affect is intrinsically productive and only secondarily captured, at a micro level, by individual consciousness and cognition, and, at a macro level, by political and cultural formations. Another is that the turn to affect is fundamentally ethical in (re)considering all the subtle, precognitive relations that are so captured and reduced. Massumi writes,

Affect is autonomous to the degree to which it escapes confinement in the particular body whose vitality, or potential for interaction, it is. Formed, qualified, situated perceptions and cognitions fulfilling functions of actual connection or blockage are the capture and closure of affect... If there were no escape, no excess or remainder, no fade-out to infinity, the universe would be without potential, pure entropy, death. Actually existing, structured things live in and through that which escapes them. Their autonomy is the autonomy of affect (1995: 96-7). 
As is well-known, this line of argumentation reaches its apotheosis in Michael Hardt's and Antonio Negri's Empire (2000), in which is posited the existence of a global affective socialist collectivity that is only momentarily captured by circuits of capital. Critics have rightfully observed the amenability of such "resistant" affectivities to further capitalist segmentation and intensification (or "endo-colonization" [Virilio 1983]), when capitalist power is not simply indifferent to them (Thompson 2005). It is not only that capitalism remains as adept as ever at incorporating that which resists it, but, more fundamentally, that the critical turn to affect largely operates according to the demands of what Jodi Dean has termed contemporary "communicative capitalism", in which "the proliferation, distribution, acceleration, and intensification of communicative access and opportunity, far from enhancing democratic governance or resistance, results in precisely the opposite, [a] post-political formation" (2005); rather than producing meaning in the interests of the public sphere, communicative capitalism circulates predominantly meaningless, feel-good affect as well as discourses legitimizing this circulation. It is thus insufficient for affect theorists to gesture ambiguously towards a precognitive realm of ethics as the simultaneous arche and telos of their critiques (Massumi 1995: 89; Thrift 2008: 10, 19, 154, 169-70).

I do not want to deny the possibility of an ethics grounded in and as affect; it has doubtless always already been practiced, for instance, in the face-to-face encounter ( $c f$. Goffman 1959). What is problematic is the almost Marcusean insistence in a substrate realm of affect (e.g. Eros) that might, with just the right approach, overcome all the world's obstacles; at one with the contemporary logic of capital, such a story moreover projects and operates within a horizon of modernist utopian desire-however diluted —and is thus grounded in the sorts of fantasies the affective realm is supposed to deny or undercut. To be sure, the modernist striving for socialist utopia has not been wholly subsumed within contemporary circuits of capital, but when this utopian striving is diffused into an argument which proposes that this utopia is already here (only momentarily unrecognized), this more radical modernist striving collapses into the sort of happy-go-lucky utopia of social and technological connectedness performed via social networks; as such, this argument effectively becomes indiscernible from the logic of contemporary capitalism. ${ }^{2}$ Instead, one should either stridently reassert the modernist striving for socialist utopia, in the logic of the contretemps, or trace the full extent of the dystopian situation. The temptations to be avoided are, on the one hand, to succumb to New Age obscurantism and/or the hopeful disposition of Hardt and Negri's Empire, and, on the other, to articulate an ultimately comforting End Point, as in apocalyptic discourses.

What theorists of affect moreover ignore with symptomatic unison is the sticky, tricky business of jouissance, which increasingly attaches itself to an array of quotidian practices, getting "between" neighbours and lovers. The matter of jouissance becomes increasingly important to analyze in the shift from a culture revolving around narratives of desire to a culture marked by the blind propulsions and circuits of drive. Desire involves the perpetual, failed chasing of its object, whereas the true aim of drive is realized $i n$ its repeated failure to reach its goal (Žižek 1999: 82). "Desire”, Slavoj Žižek writes, "desperately strives to achieve 
jouissance, its ultimate object which forever eludes it; while drive, on the contrary, involves the opposite impossibility - not the impossibility of attaining jouissance, but the impossibility of getting rid of it" (Žižek 1999: 293). Put again, "desire stands for the economy in which whatever object we get hold of is 'never $i t$ ', the 'Real Thing"'; drive "stands for the opposite economy, within which the stain of jouissance always accompanies our acts" (Žižek 1999: 291). Crucially, the formation of national and worker collectivities was made possible by modern fantasies of utopia enabling a horizon of desire; with the demise of these fantasies and the resulting suffocation of desire, we become atomized from, and hence suspicious of, one another. The Other sitting across from us "bugs" us, their jouissance violating our increasingly precarious sense of well-being (as tort lawyers working today know all too well). As the last half-century has demonstrated, the slow demise of modernity's structures of meaning is more likely to breed hatred than hopeful affect and dispositions. While this does make the appeal to an ethics of affect all the more necessary, such an appeal would be stunted if it did not fully negotiate the dystopian setting in which it is made.

As residents of Detroit live, everyday, the affective disjunct between a utopian capitalist ideal and a dystopian capitalist reality, it is not surprising that artists of the city would give body to this experience, even or precisely as it undermines the ability of the individual to integrate its experiences as belonging to a self-identified monad. It is only by following this radical pessimism, "grounded" in affects of dystopia, that it might become possible to critically articulate an alternative to capitalism; whereas Marxist theory has traditionally sought to demonstrate how the progress of capitalism inexorably leads to its revolutionary counter-logic, the focus now shifts to how capitalism's regress might lead to something other.

No hope animates this disposition, not even the most elemental utopian recognition that we have within contemporary capitalism the resources to enable an earthly utopia, a once-given that has irrevocably waned. To be sure, fleeting feelings of utopian ekstasis do come by those adjusted to living dystopically; they are affects of survivalism, of having survived, and of thereby being in the present moment (for there is no other). Something of this takes place in Detroit techno, as in rave cultures generally, but it is only in Detroit techno that a more thorough apprehension of the dystopian environment takes place. ${ }^{3}$ In short, there is no simple opposition between dystopian and utopian affects, but there is a difference in how they relate in the different eras: whereas in modernity they were, to the extent possible, split off from one another (utopia was always over the horizon, the object of desire), today utopian affect exists, to the extent that it does, in the moment, in the liberating realization that one's dystopian ex-sistence "can't get any worse". ${ }^{4}$ Rather than trying to revive modernist utopian affect in a backhanded way, we should confront the demise of modernist ideals and the resulting dystopian setting along with the fleeting utopian moments which may arise in and via this setting.

Detroit's dystopian, retrofuturist, and retrofitted environment overwhelms one's senses and abilities of comprehension. It cannot be properly captioned, framed, or cordoned off. It exceeds all attempts to place it, to make it mean once and for all. For one to make any contingent sense whatsoever of a Detroit factory returned to nature, an abstracted 
Corbusierian vision - the sort of vision that may have initially designed the factory - must be substituted with an embodied, multi-sensory perspective that traces the many competing layers and surfaces of the phenomenon. As perspectival lines do not, here, meet in the distance in order to produce a transcendent, abstracted meaning, one is presented instead with paradoxically profound layered surfaces, which contain within or across themselves several competing senses, or affects. It is, in short, an affective vision, and, with the proper reflexivity, a vision of affect, a sense of the contemporary moment as one in which structures of meaning have given way to the undecidabilities and instabilities of synaesthetic affect. With the power of sight no longer absolute, the other senses, as Derrick May suggests in this essay's epigraph, are increasingly relied upon to help one orient oneself within this increasingly dystopian environment. As vision becomes haptic, one's ears perk up to hear what's going on, and down, within a newly-emergent acoustic space. Marshall McLuhan (1966) defined our emergent acoustic space as replacing one dominated by the linearity of Renaissance vision; in the place of reading information line-by-line in the masterly production of meaning, one must increasingly, and precariously, scan the environment for patterns. Techno could be seen as the music of acoustic space inasmuch as it creates repetitive patterns within and between tracks, in which listening, qua scanning, involves recognizing and affectively responding to minute differences.

\section{TeChNo Ambivalence: Utopia/DYSTOPIA}

My conservative reactionary friend

The end don't justify the means you understand

You take the butter from the table buy a gun

You think the status quo will be there when you're done

You buy the missile buy the laser buy the tank

Evict the widow put the money in the bank

You do it all in the name of economics economics economics

Well it's just industrial lies hidden behind your eyes (x2)

—Cybotron, "Industrial Lies"

Detroit TECHNO is widely acknowledged to have had an ambivalent relationship with technology. The sons of unionized African American auto workers, the first wave of Detroit techno producers and DJs, including Juan Atkins, Derrick May, and Kevin Saunderson, observed how robotics were gradually replacing humans on the line, but, rather than simply opposing technological development it was ambivalently embraced as the means to survive their situation and orient themselves towards the future. As both commentators and the artists themselves have remarked, this sensibility was informed and influenced by Alvin Toffler's Future Shock and The Third Wave, early video games, and repeat viewings of early 80s dystopian films like Blade Runner (Ridley Scott, 1981) (Albiez 2005: 131; Dery 2002; McCutcheon 2007: 266; Walmsley 1999). Certainly Detroit, in its being not only 
effectively run but designed by the big three auto manufacturers, was well-suited to this quasicyberpunk imaginary. I write "quasi-cyberpunk" since, in the popular understanding, the cyberpunk narrative typically involves the protagonist's gleeful overcoming of his initially bleak situation through his clever appropriation of technology; it is not evident that Detroit techno artists embody this view, nor is it apparent from their music, which, after all, knows no end to its "narrative", no final "sublation" of the situation it addresses and cathects.

Jeff Mills, an influential Detroit techno producer and DJ, in an interview discusses a formative childhood experience, where, to get away from the 1967 "race riots" in Detroit, his family left for Montreal where they took in Expo '67's utopian visions of the future. The lengthy passage is worth quoting unedited to preserve the manner in which Mills jumps back and forth from his experience of Detroit to his experience of Expo '67:

Well for me, maybe one of the most influential things that happened was during the riots in Detroit in 67. My parents decided to pack the family up and take the family out of the country because it was too violent in Detroit-it primarily happened in our neighborhood in Detroit, where all the bombings and all the police and the army came in, and they declared martial law. You could not leave your house. It was the summertime, there was no way you could keep six kids in the house in summertime, it was just impossible. So they decided to make a vacation, and they took all the kids to Expo, in Montreal, an exhibition on Futurism - architecture, technology. And I must have been six or seven at that time.

In Detroit, you had to keep all the shades down, because there were snipers. If army men thought they saw something in the window that was pointed at him, he had the right to shoot at it. So we had to keep the shades down, in a dark house, in the middle of the summer, we had no air conditioning. There were no supermarkets, they were closed. It was like a warzone. The army was using the school ground for landing helicopters. And they were marching down the middle of our street, tanks were coming down our street, going to the worst part of the riot.

We stayed there for a few weeks. It was maybe most impactful because you go from one very bleak, very bad situation, to something very bright, very promising. For a kid, six or seven, it was like Disneyland, these big installations, big exhibition halls (in Walmsley 1999).

It is apparent that, for Mills, these two wildly divergent experiences were and remain inextricably related in his mind, and if this episode was, as he says, formative for his development, it would appear to be so in the sense of suspending him between a dystopian sense of the real and a modernist utopian vision of technology. Technology, in the foreboding form of tanks rolling down his street, was Mills' enemy, but it was also, as Expo '67 taught him, his means to, if not salvation, survival.

To the extent that African American Detroit techno artists ambivalently embraced a technological future, links have been drawn to the Afrofuturist science fiction premises of 
Samuel Delany and Octavia Butler. Discussing Afrofuturist themes within contemporaneous hip hop, Tricia Rose suggests,

What Afrika Bambaataa and hip-hoppers like him saw in Kraftwerk's use of the robot was an understanding of themselves as already having been robots. Adopting 'the robot' reflected a response to an existing condition: namely, that they were labor for capitalism, that they had very little value as people in this society. By taking on the robotic stance, one is 'playing with the robot'. It's like wearing body armor that identifies you as an alien: if it's always on anyway, in some symbolic sense, perhaps you could master the wearing of this guise in order to use it against your interpolation (in Dery 1994: 213-14. italics in original).

Of course, Kraftwerk was also a foundational influence on early Detroit techno producers. At the end of High Tech Soul (Gary Bredow, 2006), a film documentary about Detroit techno, May muses that "when our shit was first heard it must have sounded like alien music ... which is why", continues May as he looks at the camera, "we're sitting here today". Likewise, on his hugely influential Detroit radio show, Charles Johnson, better known as the Electrifying Mojo, theatrically and ritualistically began each show giving the impression, with the aid of sci-fi soundtracks and classical music, that he was arriving in his "mothership". According to an Afrofuturist outlook, Detroit musicians reclaimed their outsider status to highlight the incongruities and injustices of world as they saw them.

In a key essay that appeared in The Wire in 1992, Mark Sinker observed that,

the central fact in Black Science Fiction-self-consciously so named or not-is an acknowledgement that Apocalypse already happened. .. . Black SF writers ... write about worlds after catastrophic disaster; about the modalities of identity without hope of resolution.

To the extent the apocalypse has already occurred, one cannot exist outside it and its resulting dystopia; there can be no purity of critique. In the place of bemoaning the technological advances of corporations and the military-industrial complex, one discerns ways, or tactics, to subvert them from within. Although Detroit techno has remained fiercely independent since its inception, this would become most explicit with Underground Resistance (UR), part of the second wave of Detroit techno, whose overt militancy addressed the military-industrial complex to the extent the latter preceded and predetermined quotidian experience. While borrowing practices from established record labels, this militancy also led UR and Submerge, Detroit techno's foremost record distributor, to vigorously fight a major record label, Sony, when it tried to steal and mass market "Knights of the Jaguar" (see McCutcheon 2007).

Sinker's argument should be affirmed against others arguing for the utopian character of Detroit techno. In the most comprehensive text on the genre and its progenitors, Techno Rebels, Dan Sicko too casually suggests that techno is utopian in its aspiration for a future in which race is no longer an issue (2010: 12). While this suggests a modernist utopian 
worldview, it could be observed that race necessarily becomes less visible in postmodern dystopian situations to the extent that in such situations looking past the colour of the other's skin is less an ideal realized than an elementary requisite for survival. In Detroit techno, the overwhelming affect remains that of dystopia; certainly, there are few moments in which a utopian reversal or sublation of the dystopian situation could be said to take place. When utopian affects $d o$ circulate, they are related to a survivalist disposition at odds with modernist utopian striving (though they are perhaps associated with a certain melancholia for the demise of the modern project, as in the experience of being moved by tracks like "Strings of Life" or "Knights of the Jaguar" surrounded by anonymous others in the prototypical dark of the techno party). Utopian affects emerge here only upon recognition of the dystopian moment, when one is at once free and compelled to traverse the inertia of the present and the future onto which it "opens". These are affects born of survivalism, of surviving the end of the world, of persisting within a worldless world, now. Living in the expanded dystopian present and acoustic space of Detroit, Detroit techno artists respond by producing and playing music which further opens up this present and space to one's experience (see Frith 1996: 157); the result is that the impossible, unintrojectable dystopian Real becomes minimally apprehended by an embodied consciousness.

\section{Sharevari Vs. Alleys of Your Mind: Breaking With History and Subculture, or TeChNo as ART AND TRUth-EVEnT}

Techno was a musical thing. There wasn't no culture—no whistles, no Es....

-Eddie Fowlkes (in Reynolds 1999: 71-2)

There's a very strong, individualistic mentality here in Detroit. You develop it without noticing. I didn't notice it until I went overseas, where everyone has several real close, dear friends. Here it's like Vietnam-I'm not getting close to anybody.

-Mike Banks, co-founder of Underground Resistance (in Sicko 2010: 101)

Alleys of your mind

Paranoia right behind

Alleys of your mind

Out of sync out of rhyme

—Cybotron, "Alleys of Your Mind"

IN ADDITION to being associated with cyberpunk and Afrofuturism, a certain historicization of Detroit techno is often made with reference to the middle-class "preppy" social gatherings and parties that spread around Detroit's suburbs in the late 1970s and early 1980s, a time, like many others, in which Detroit youth had no other option than to creatively hold and promote their own parties. In Techno Rebels, Sicko begins by discussing these high school 
social parties in which early techno DJs participated. Although there is ongoing debate within the techno universe as to whether "Sharevari", by Number of Names, or "Alleys of Your Mind", by Cybotron, is Detroit techno's first record, Sicko discusses "Sharevari" first since it came out of - and was oriented to-the social party scene. In contrast to "Sharevari's" lyrics promoting a consumerist paradise of designer sheets, Porsches and fine wines, however, "Alleys of Your Mind" involves such a paranoiac turn inward that the disjunct between the two tracks should be more explicitly considered. For, if "Sharevari" and the high school party circuit involved scenes of dialectical recognition and consumerist aspiration, ${ }^{5}$ the worldview manifest in "Alleys of Your Mind" points instead to a city of atomized individuals who could no longer recognize one another, but who could only trace the consequences of this demise (for instance, by following the voices/alleys in their head/minds). It is an entirely different sensibility, mobilizing affect along an alternate path. Though the biographical histories of the artists who would become Detroit's well-known techno DJs do undeniably overlap the high school party circuit, rather than draw a straight line from one to the other it seems more important, in any historical account of techno, to delimit techno's break with this circuit.

Nevertheless, when arguments about Detroit techno's middle-class aspirational "origins" are made, it seems only logical to discuss the subculture in terms of "subcultural capital". Drawing from Pierre Bourdieu's analysis of taste cultures in Distinction (1984), Sarah Thornton argues that subcultures distinguish themselves by their particular taste formations, in which esoteric musical knowledge serves as a form of capital that can be used in the production of identity and, in some cases (for example, with producers, DJs and promoters), actually translated into economic capital (1995: 11-12). From this perspective, middleclass Detroit techno artists are said to have realized their "Europhile fantasies", piqued by Kraftwerk and Italian fashions, through their subcultural production (Reynolds 1999: 14, $23,114)$. While this path of analysis is entirely appropriate to the study of the fashionable and Europhile social party circuit, it is not clear that it is the right one to follow in the analysis of the origination and initial development of Detroit techno. As Adorno would note, such historicization risks forcing identity across divergent phenomena, reducing different languages and events to the same currency (exchange-value). Indeed, it seems more important to delineate, in our histories, those points at which a gap is introduced into the smooth flow of history, and in which, as consequence, the accumulation of subcultural capital is interrupted, the currency no longer recognized, or, at the very least, devalued. It goes without saying that, failing to do so, we render ourselves unable to discern the emergence of anything New; everything can only be the inevitable result of prior histories, existing links and mutual influences. Rendering the scholar (the conduit, in Lacan's terms, of the discourse of the university [see Žižek 2006]) infallible-she can never be caught unaware, always able to historicize any and all developments as having $\mathrm{X}, \mathrm{Y}$ and $\mathrm{Z}$ influences without having to articulate and defend any radical truth-claim-this power is, ultimately, one of dissimulation; lurking below this veneer of false equivalences lies radical difference and negativity (non-identity, to use Adorno's term). 
Elsewhere, I argued that the commonplace focus of cultural studies on the meaning of the punk subcultural style elided a recognition of punk's break with meaningful history, as manifest in the scene surrounding the Sex Pistols in 1976 (Pope 2009). The subsequent focus of cultural studies on subcultural markers of identity, I argued, contradicted and finally elided the field's initial apprehensions of the aggressive meaninglessness of this scene and what this aggressivity indexed: the demise of a sociopolitical order in which a meaningful statement might be addressed, made and finally recognized (thereby indexing the "demise of Symbolic efficiency" [Žižek 1999: 322]). For instance, in Subculture: The Meaning of Style, a foundational text not only of the study of punk but of cultural studies as such, Dick Hebdige moves immediately from recognizing the meaninglessness of the punk style to discussing its potential polysemy (1991: 117-9). The future of cultural studies was informed by this gesture, even or especially as it elided the initial recognition; as cultural studies locked down the meaningfulness, the identity, of punk, it locked down its own, remaining haunted by what it originally sought to exclude.

Techno, I would argue, is even more demanding of a form of analysis that would not read it for the meaning of its style, for its desire. Whereas punk, even before it evolved into a subculture and a uniform, involved dialectical scenes of recognition in which participants went to see, to be seen, and to be seen seeing, the techno scene is - however paradoxicallymarked by the relative absence of such scenes of recognition. While there is no doubt that techno artists at times congregated around certain key locales, it is also evident that Detroit artists have remained largely independent of one another, as Banks suggests in the epigraph to this section. ${ }^{6}$ Sicko himself notes that, in contrast to the global rave cultures which spawned from techno, Detroit techno was free from the "trappings of subculture" - though he does not consider what this entails for his earlier attempt to place techno wit hin the quasi-subcultural trappings of the high school party circuit (2010:91).

Put simply, predominant theories of subculture, rooted in a modernist paradigm, are inappropriate to the analysis of postmodern (or post-postmodern) cultural phenomena. Within the modernist framework, youth, who cannot simply voice their frustrations and desires via the outlets operated and controlled by the "parent culture", are seen to channel their plaints into stylistic markers of identity. For the subculture as for the critic reading the subculture, the youthful rebellion is ultimately a utopian striving which, far from undermining the parent culture, ultimately reaffirms modernity's ethos and spirit. As such, the subculture is easily historicized, simply placed within a progressive history running parallel to official conservative culture. Punk's radical, insistent negativity, however, breaks with this; its repeated assertion of "no future" renders such analysis impotent. To put it tautologically, to the extent it announces-better: realizes-the end of history, it cannot be easily historicized. And in this regard, techno goes even further in initially accepting the end of history and moving on to consider the dystopian, retrofitted reality which is its consequence; where punk rails against the end of history, techno blips, bleeps and grooves. 
There is no question, of course, that punk did form a recognizable subculture and identity; indeed, it could be argued that the music industry and the mainstream media were desperate to identify the contours of the 1976 punk scene, not only in the interests of repackaging the scene for profit but to sublate and attenuate its radical force of negativity, to turn early punk's recognition of the social's demise into merely another youth rebellion that had a rightful place within a larger social order. Similarly, as Detroit techno is now nearing thirty years of age, markers of its identity have been produced and continue to be circulated, though it nevertheless remains the case that there is no recognizable style for Detroit techno fans (whereas one can detect ravers at a glance). Moreover, Detroit techno remains invisible within American culture, nonexistent for the "parent" culture, while the attention Detroit techno received on the other side of the Atlantic-first in the UK, but now predominantly in Germany-was fortuitous and always subject to something being lost in translation. That Detroit techno artists have always expressed puzzlement that their music could be so ignored at home and yet relatively well-received in Europe indexes the inapplicability of the subculture model as the primary means by which to analyze the phenomenon. The lines of desire, when not confused and crossed, were and are nonexistent.

It might be emphasized that it is common to hear Detroit techno artists articulating their differences from the banalities of trance and popular music generally, as though to reproduce and affirm their particular taste culture and identities. However, in appropriating Adorno's aesthetic theory I would suggest that Detroit techno is altogether more "serious" and artistic than a genre like trance. Adorno's aesthetic theory, formed through the admixture of the philosophies of Kant, Hegel and Marx, stipulates that genuine art must enjoy formal autonomy from society (Kant) while nevertheless remaining socially embedded (Marx) and, thus, intellectually important (Hegel). In this simultaneous necessity and illusoriness of the artwork's autonomy, the artwork emerges as the "social antithesis of society" (1997: 9), expressing, through its form, the contradictions of society. This truth content of the artwork is neither unchanging nor simply a human construct. Adorno writes,

Art can be understood only by its laws of movement, not according to any set of invariants. It is defined by its relation to what it is not. The specifically artistic in art must be derived concretely from its other; that alone would fulfill the demands of a materialistic-dialectical aesthetics. Art acquires its specificity by separating itself from what it developed out of; its law of movement is its law of form. It exists only in relation to its other; it is the process that transpires with its other. Nietzsche's late insight, honed in opposition to traditional philosophy, that even what has become can be true, is axiomatic for a reoriented aesthetic. The traditional view, which he demolished, is to be turned on its head: Truth exists exclusively as that which has become. (1997: 3)

Nevertheless, for Adorno, popular music could not reach the level of art, being standardized in such a way that reception of the work could only focus, momentarily, on the fragment, and never the work as a whole (1941: 19); ${ }^{7}$ there could be no question, then, of the- 
nonexistent-work giving body to the contradictions of society. Needless to say, this position stands at some remove from the presentiment of art as a process of becoming; if a group of people delimit a work or body of works as-relative to the commercial mainstream-art, could that not make it so? When aficionados of Detroit techno oppose it to popular music, I would suggest that they do so as the means to mark its difference as art; while this does inevitably serve to produce a distinguishable taste culture, the more fundamental dynamic involves a drive to secure the genre as art and as thereby expressing something of the contradictions of contemporary society. To be sure, they do not thereby mark the musical form as high art, but rather as semi-popular art. As Simon Frith rightfully observes, in rejecting high art and rushing to celebrate the popular (and in particular the reception of the popular), many works of cultural studies have eliminated the possibility of recognizing superior forms of popular culture, the "unpopular popular" that "challenge experience" and draw our attention to the contradictions of social life. Such forms, Frith continues, should be "taken seriously" on their own terms and not merely insofar as they are consumed by audiences according to a resistant modality $(1996: 20) .{ }^{8}$ Detroit techno is one such form.

Ultimately, the taste culture at work in this instance is not one whose primary logic is of producing and buttressing the self who states that Detroit techno is "serious" music, but one in which the fundamental gesture is to produce and protect the music as art which itself expresses the demise of the individual articulating this difference. This is why Detroit techno artists once studiously protected their incognitos. The music, and the affect around which it circulates, is-or at least was-meant to "speak" for itself, precisely to the extent that part of what it expressed was the demise of coherent identity in the fading of the modern project. Adorno and Badiou argue alongside one another: when contemporary artists express the ongoing differentiation of Detroit techno from other forms of music, they are, in Adorno's sense, distinguishing the music as art while indexing the ways in which it expresses the truth of the contemporary social condition, while, in Badiou's sense, they are affirming their fidelity to the artistic truth-event of Detroit techno while working through its consequences (2005: 12).

\section{The Music, the Lost Funk and the Post-Human}

Technify your mind... Don't let them robotize your behind.

—Cybotron, "Enter"

THE TECHNO SOUND, I observe in what follows, is marked by its relative absence of lyrics, its use of retrofitted equipment, its $4 / 4$ beat, its repetitiveness, and its modulated industrial noises such as alarm bells or sirens, all of which combine to produce a post-human, though funky, musical form appropriate to a dystopian environment.

For the most part, techno is a lyric-less form. Techno's first record, Enter (in a 1990 re-release it was renamed Clear) by Cybotron, featuring "Alleys of Your Mind", is the only 
record to have lyrics - and earnest ones at that-track after track. As such, it meaningfully points to the sorts of affects later techno would no longer require language to achieve; indeed, words would become superfluous, techno no longer requiring-a now in any case impotent and delusional, if no less dangerous and manipulable-logos. When later techno tracks do include "lyrics", it is most often as single words repeated so many times that the signifier is considered as such, devoid of any signified. In this sense, then, techno's first record was a "vanishing mediator" (Žižek 1991), the consequences of which were worked through in all subsequent techno art.

Throughout its "history" techno warns of our technological future-a future which is felt, according to a dystopian outlook, to be already, irrevocably, "here"-while advocating a DIY techno spirit in confrontation with this future. Rather than using state-of-the-art technology, which they could not in any case afford, Detroit techno producers relied on the often antiquated tools they had available at hand, typically using them in ways the creators did not and could not have imagined. The Roland TR-303, TR-808 and TR-909, for instance, were initially developed to faithfully reproduce the sound of bass and drums, failing miserably in this function; they were quickly appropriated by techno producers for their synthetic sounds. Furthermore, nearly all techno records were produced by the late Ron Murphy in his studio, Sound Enterprises; while most of his techniques remain secreted, he has suggested that the specificity of the Detroit sound was mostly the result of antiquated and/or DIY, retrofitted equipment: "The sound is a little different because I use a system that nobody else in the world uses... I'm the only one cutting ... so it's tuned a certain way. Also, the amp blew early on so we made our own amp modules, which changed the sound" (in Sicko 2010:111). According to a cyberpunk spirit, Murphy at once indexes the importance of the unique, retrofitted equipment in his studio and his particular and subjective manner of cutting records.

The most common musical element of techno, of course, is its four-on-the-floor beat, producing a contradictory sense of forward momentum and circularity, which is itself accentuated by the uninterrupted DJ set lasting several hours. By contrast, a genre like drum ' $n$ ' bass produces, on account of its breakbeats, a sense of disjuncture allowing for a more definitive sense of forward progress, making it more amenable to narrative structuration and call-and-response devices. The differences between techno and a genre like trance are more subtle. Trance, like techno, employs a $4 / 4$ beat, but unlike techno the typical trance track develops more of a song structure with its escalating melodies and highs and lows, the effect of which is to produce a sense of-utopian, harmonious, transcendent-elation. Generally speaking, the techno track remains grounded with its more minute differences (see Butler 2006: 227-240). Indeed, the ultimate techno invention may be the "locked groove", created as an aid to techno DJs in their live sets. Murphy explains,

I had been noticing that a lot of [techno] was very repetitive-I couldn't help but notice! I kept thinking about that. Jeff Mills came in and said, 'I got a thing here called "The Rings of Saturn". What can we do different? I said, 'All your stuff is these loops, 
right? I wonder if I can loop it on a record in one turn-like a ring'... I played the loop and Jeff looked up 'cause he noticed that something was supposed to change. It was perfect. 'That's the loop I was telling you about', I said. He jumped up and said, 'Do you know what this means?!' (in Sicko 2010: 110)

What it meant, of course, was the total eclipse of the typical song structure, along with the meaning such narrative structuration implied and guaranteed-there being no better example of the shift towards a culture marked by the propulsions of drive than the locked groove and the discussion surrounding it.'

In Adorno's terms, in revolving around these minute differences the techno listener devotes attention to each fragment (e.g. industrial noises) in its integral relation with the whole of the individual track; in turn, each track "fragment" is perceived in relation to the whole of the DJ set. By contrast, the listener of a genre like trance may tune out for the build-up of a track and only tune back in for those moments of transcendent elation. It is doubtless for this reason that trance is, relative to techno, an extremely popular form of electronic dance music, with its fragmented riffs exploding from the confines of rave culture to Top 40 radio. Detroit techno, as even its detractors index in their denouncements that "it all sounds the same", is a more demanding form of music; if, for its critics, the music is insufficiently pseudo-individualized-it being, in their analysis, not individualized at all-this very repetition is what allows its proponents an "aha!" moment in which they recognize and reflexively apprehend the nuanced pattern of each track (typically in relation to the DJ set), a moment in which the music is thereby imbued with soul and funk.

Of course, "techno" is often seen as a soulless form. Many commentators have described a disjunct between Detroit's musical history and techno, often using one comment by Juan Atkins to back the claim:

Berry Gordy built the Motown sound on the same principles as the conveyor belt system at Ford's... Today they use robots and computers to make the cars. I'm probably more interested in Ford's robots than Berry Gordy's music. (in Cosgrove 1998: 88)

Given the propensity with which this quote has circulated, Atkins has suggested that he has been misinterpreted, implying that techno is in fact inherently soulful and funky. Derrick May suggested as much when he famously quipped that techno "is just like Detroit, a complete mistake. It's like George Clinton and Kraftwerk stuck in an elevator" (in Cosgrove 1998: 86). Indeed, it is-at least in part-via its very repetition that the music becomes funky and soulful.

This soulful/funky element becomes most evident in a variant of Detroit techno known as "minimal techno", part of Detroit techno's second wave. For the uninitiated, minimal techno sounds very repetitive; for its producers, DJs and fans, however, this repetitiveness does not preclude the possibility of it being/becoming soulful—just the opposite. Robert Hood, one of Detroit's more well-known minimal producers, describes minimal techno's raison d'être: 
I think [Daniel Bell] and I both realized that something was missing-an element ... in what we both know as techno. It sounded great from a production standpoint, but there was a "jack" element in the [old] structure. People would complain that there's no funk, no feeling in techno anymore, and the easy escape is to put a vocalist and some piano on top to fill that emotional gap. I thought it was time for a return to the original underground. (in Sicko 2010: 140)

For Hood, typical signifiers of soul get in the way of genuine soul or funk. As he also intimates, minimal techno is not a new form of techno but a return to Detroit techno's roots, another back-to-the-future return from the technical perfection of contemporary production to the "'jack' element" of Detroit techno's first wave. In creating new, future thinking techno, Hood, and Bell, another minimal techno producer, thereby affirm their fidelity to the retrofuturist imaginary—and reality—of techno's funky beginnings. From a production standpoint, this "soul" or "jack" is, in addition to being a function of repetition, to some extent the result of this retrofitted retrofuturism, of working with and imaginatively reusing antiquated and accidental tools to remediate visions of the future.

If Detroit techno's soul is partly the result of its repetitiveness and its imperfect recording technologies, it is also a function of what is perhaps the second most common element (next to the $4 / 4$ beat) in techno: the modulated alarm bell, siren or sonar. It might seem perverse to think that one could find soul in the sound of alarms, but a great many techno tracks are marked by some form of repeated, modulated alarm/siren/sonar either taking the form of a melody and/or taking the place of what some would see as the place of the melody. It is as though, while one's body is dancing (or at least being affected on a "virtual synaesthetic" level [Massumi 1995: 96]) on account of the 4/4 beat, one is continually being warned, at the level of the (pseudo-)melody, of the danger that lies ahead. Of course, this danger is never (or in any case rarely) specified or articulated as such; indeed, from one angle the warning, of the technological future, is a warning of itself qua techno track, a warning of that to which one is figuratively or literally dancing.

And as such, one is always already surviving this dystopian situation; dancing, one is asserting one's post-human "humanity", glitching the matrix, in perfect parallel to the techno producer asserting her "humanity" by reproducing techno's original "jack element" and to the animated DJ "jacking" the highs, lows and mids behind the decks. This triangulation, however, does not produce a common humanity (a "whole") anchored in consensual fantasy and desire; on the contrary, the three elements relate without relating in the circle-and, at times, in the reflexive apprehension of the circle-of drive. While largely overcoming the divide between producers and consumers typical of consumer capitalism, no humanism lurks in this relation. One only becomes or senses oneself as human, as alive, in the very moment one acknowledges one's co-imbrication with technology; one only becomes human in this act of reflexive apprehension, in this testimony, not unlike the replicant Roy Batty (Rutger Hauer) in the penultimate scene of Blade Runner when he testifies to all the things us "people wouldn't believe", teaching the ostensible protagonist, Deckard (Harrison Ford), what it "is" 
to be-or continually become-human. The cyborg, of course, is technology as other and the other as technology, becoming human, in this reading, through the act of testimony, testifying to the impossible, the unknowable, the unbelievable - the patterns it has recognized and the alien within (Pope 2008). As such, it is no surprise that Detroit techno artists so often point to Blade Runner as a foundational influence; Batty jacked the decks.

It is a commonplace to suggest that Detroit techno was developed as an impure form, incorporating elements from electro, Italo disco, and Chicago house, as well as that it has become even more so in its hybridizing global collaborations. But techno was not (like "electronica") a form devised by music industry insiders to sell a pseudo-individualized product to unassuming and distracted masses; it was, and remains, a radically differentiated and largely unpopular form that expresses a wholly different sensibility than its many admitted influences, and one that, moreover, for many continues to express this different sensibility according to an Adornian and Badiouan logic. According to this logic, the form may, at some point, no longer be considered art; its relation to social contradiction may be diminished with its one-time followers abandoning it. Perhaps this has already started to happen to the extent that many of Detroit techno's foremost proponents have left Detroit and increasingly embraced celebrity DJ culture, but the situation is, for the moment, undecidable, and as such open to ongoing intervention and retrofuturist gestures of "going back to the roots".

\section{Conclusion: Politicizing the Dystopian Aesthetic}

IT IS SOMETIMES SAID, of those who find enjoyment or something of their own experience reflected or refracted in Detroit, that they are "trauma tourists", taking pleasure, if not, quite, Schadenfreude, in the misfortunes of others. Romanticizing or elegizing a dystopian environment, for such critics, involves a diversion of attention from the immediate need to address and redress the city's socioeconomic injustices. Yet Detroit, by its nature, is aestheticized. The city was a universally-recognized work of art when it was designed and realized as the modernist future of the Western world, and it becomes even more aestheticized as this once utopian vision/realization flips over into its opposite, a realization and a vision of dystopia. It is the ultimate retrofuturist environment, upending our masterful powers of thought and vision and our attempts, in this sublime encounter, to finally sublate or overcome our initial amazement and bewilderment. Detroit remains awesome, tremendous, terrifying, voiding the self who sought to understand and overcome. As one moves through Detroit, one thus cannot but recall the many science fictional films that provide visions of the dystopian, retrofuturist future; while such remembrance occurs, in part, because many of these films themselves appear to reference Detroit, it also marks an attempt to frame and frame-off one's disjointed experience, to cohesively, and meaningfully, (re-)join/re-member it together. But Detroit-like, as it happens, Blade Runner (see Pope 2010) -cannot be meaningfully framed (off), and, as such, it reminds one of the ontological oblivion of late capitalism while also revealing the subjective mode appropriate to this encounter: techno survivalism. Rather than shy away from a consideration of one's phenomenological encounter 
with the Real of Detroit, under the pretension that one is thereby committing oneself to more "serious" intellectual labour, then, it should be explicitly negotiated, without guarantees. Detroit's immediate problems do need serious and immediate consideration, but attending to these issues should not detract our eyes and ears from recognizing Detroit's aesthetic, dystopian dimension, and what this dimension indexes for our precarious futures; doing so would mean missing out on Detroit's foremost cultural contribution since Motown to the world. It is, in the end, a question of politicizing - without hoping to overcome-aesthetics and this sticky, implacable affect of the dystopian Real, this revenant from the past from the future.

\section{ACKNOWLEDGEMENTS}

I am grateful to two anonymous reviewers for their comments.

\section{NOTES}

1 Although the expression "late capitalism", popularized by Ernest Mandel and Fredric Jameson (1991), has often been criticized given capitalism's apparent persistence, it returns as the most apt term to describe a situation of capitalism's paradoxical demise and persistence, its persistent demise and seemingly infinite regress.

2 As I edit a final draft of this essay, for the last two weeks television networks have been endlessly repeating how the uprising/revolution in Egypt was preconditioned, even necessitated, by social media.

3 The affective stance of European techno, by contrast, seems to slip between being the result of a felt sense of the premature demise of the modern project and of a sense of modernity's triumphant realization with the fall of the Berlin Wall and the reuniting of Europe; in such aporetic con-fusion, participants cannot come to a recognition of underlying cultural dynamics.

4 This recognition marks a key scene in Fight Club (David Fincher, 1999), a film that often looks like it takes place in Detroit. Tyler Durden, for instance, appears to live, or squat, in the prototypical Detroit "home".

5 See, for instance, this video of "Sharevari's" debut on "The Scene", a local Detroit dance television

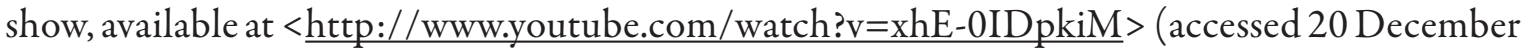
2010).

6 It is worth remembering, in this context, that one defining element of techno parties is the absence of light and the consequent invisibility of one's "fellow" party-goers; famously, the Music Institute, the Detroit techno club for one short year between 1988 and 1989, had only one strobe light pulsating through the night, while Hawtin's renowned parties at the Packard plant took place in near-total darkness. Needless to say, dialectical recognition is stunted in such environments: while one can at moments see, and be seen, it becomes more difficult to be consistently seen seeing. It should thus not come as a surprise that the techno scene did not mutate into a recognizable subculture with its clearly-defined markers of identity.

7 To be sure, to employ Adorno's aesthetic theory in the analysis of Detroit techno requires rejecting 
his dismissal of rhythmic music as expressing a "desire to obey", a position that appears entirely superfluous to the core of his aesthetic theory.

8 In rehabilitating Adorno's aesthetic theory with regards to popular music, Frith argues that there is a utopian element to such forms. In the case of Detroit techno, it is a dystopian affect which dominates.

9 In another moment of prescient ingenuity, Murphy also created a record that played inside out (Sicko 2010: 110).

\section{REFERENCES}

Adorno, Theodor. 1941. "On Popular Music". In Studies in Philosophy and Social Science vol. 9, 17-48. Cambridge: Cambridge University Press.

- - - 1997. Aesthetic Theory. London and New York: Continuum Press.

Albiez, Sean. 2005. "Post-soul futurama: African American cultural politics and early Detroit techno". European Journal of American Culture 24, no. 2.

Badiou, Alain. 2005. Handbook of Inaesthetics. Stanford: Stanford University Press.

Benjamin, Walter. [1940]. “Theses on the Philosophy of History”. < http://www.sfu.ca/ andrewf/ CONCEPT2.html> (accessed 20 December 2010).

- - - 1978. "The Work of Art in the Age of Mechanical Reproduction". In Illuminations, ed. Hannah Arendt, 217-251. New York: Schocken Books.

Bourdieu, Pierre. 1984. Distinction: A Social Critique of the Judgement of Taste, trans. Richard Nice. Cambridge, Mass.: Harvard University Press.

Bowman, Zach. 2010. "Detroit still hunting down Packard plant owner”. Autoblog. < $\underline{\text { http:// }}$ www.autoblog.com/2010/07/10/detroit-still-hunting-for-packard-plant-owner/\#comments $>$ (accessed 20 December 2010).

Butler, Mark. 2006. Unlocking the Groove: Rhythm, Meter, and Musical Design in Electronic Dance Music. Bloomington: Indiana University Press.

Cosgrove, Stuart. 1998. "Seventh City Techno". The Face 97 (May).

Dean, Jodi. 2005. "Communicative Capitalism: Circulation and the Foreclosure of Politics". Cultural Politics: an International Journal 1, no. 1 (March): <www.johnbr.com/files/ communicative_capita21d5bb.doc> (accessed 20 December 2010).

Dery, Mark. 1994. "Black to the Future: Interviews with Samuel D. Delany, Greg Tate, and Tricia Rose". In Flame Wars: The Discourse of Cyberculture, ed. Mary Dery. Durham NC: Duke University Press.

- - 2002. "Black to the Future: Afro-Futurism 1.0". < $\underline{\text { http://detritus.net/contact/ }}$ rumori/200211/0319.html> (accessed 20 December 2010).

Eshun, Kodwo. 1998. More Brilliant than the Sun: Adventures in Sonic Fiction. London: Quartet.

Frith, Simon. 1996. Performing Rites: On the Value of Popular Music. Cambridge, Mass.: Harvard University Press.

Goffman, Erving. 1959. The Presentation of Self in Everyday Life. New York: Anchor.

Hebdige, Dick. 1991. Subculture: The Meaning of Style. London: Routledge. 
Herron, Jerry. 1993. AfterCulture: Detroit and the Humiliation of History. Detroit: Wayne State University Press.

Jameson, Fredric. 1991. Postmodernism, or, The Cultural Logic of Capitalism. Durham: Duke University Press.

Massumi, Brian. 1995. “The Autonomy of Affect”. Cultural Critique 31 (Autumn): 83-109.

McCutcheon, Mark A. 2007. “Techno, Frankenstein and copyright”. Popular Music 26, no. 2: 259-280.

McLuhan, Marshall. 1966. Understanding Media: The Extensions of Man. Toronto: McGraw-Hill. Negri, Antonio, and Michael Hardt. 2000. Empire. Cambridge, Mass.: Harvard University Press.

Pope, Richard. 2008. “A Cyborg's Testimonial: Mourning Blade Runner's Cryptic Images”. FilmPhilosophy 12, no. 2.

- - . 2009. "Realizing the Scene: Punk and Meaning’s Demise". International Journal of Žižek Studies 3, no. 1.

- - - 2010. "Affects of the Gaze: Post-Oedipal Desire and the Traversal of Fantasy in Blade Runner". Camera Obscura 25, no. 1: 69-95.

Reynolds, Simon. 1999. Generation Ecstasy. New York: Routledge.

Sicko, Dan. 2010. Techno Rebels: The Renegades of Electronic Funk, 2nd. Ed. Detroit: Painted Turtle.

Sinker, Mark. 1992. "Loving The Alien-Black Science Fiction”. The Wire 96 (February). < http:// www.thewire.co.uk/articles/218/print> (accessed 20 December 2010).

Thompson, Paul. 2005. "Foundation and Empire: A Critique of Hardt and Negri”. Capital \& Class 86 (Summer): 73-98.

Thornton, Sarah. 1995. Club Cultures: Music, Media, and Subcultural Capital. Cambridge: Polity Press.

Thrift, Nigel. 2008. Non-Representational Theory. London and New York: Routledge.

Virilio, Paul. 1983. Pure War. New York: Semiotext(e).

Walmsley, Derek. 2009. “Jeff Mills Interview”, The Wire 300 (February). < http://www.thewire. co.uk/articles/2035/> (accessed 20 December 2010).

Žižek, Slavoj. 1991. For They Know Not What They Do. London and New York: Verso Books.

- - - 1992. Enjoy Your Symptom! New York and London: Routledge.

- - - 1999. The Ticklish Subject: The Absent Centre of Political Ontology. London and New York: Verso.

- - 2004. Iraq: The Borrowed Kettle. London: Verso.

- - - 2006. “Jacques Lacan's Four Discourses”, Lacan.com. < http://www.lacan.com/zizfour.

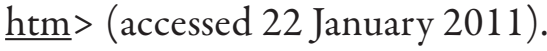

\section{FILMOGRAPHY}

Bredow, Gary. 2006. High Tech Soul. USA: Plexi. <http://www.imdb.com/title/tt0877337/> Scott, Ridley. 1982. Blade Runner. USA: Warner Bros. < http://www.imdb.com/title/tt0083658/> Temple, Julien. 2010. Requiem for Detroit. UK: BBC.<http://www.imdb.com/title/tt 1572190/> 